From materials development to their test in IFMIF: an overview

This article has been downloaded from IOPscience. Please scroll down to see the full text article.

2011 Nucl. Fusion 51113006

(http://iopscience.iop.org/0029-5515/51/11/113006)

View the table of contents for this issue, or go to the journal homepage for more

Download details:

IP Address: 85.7.200.188

The article was downloaded on 13/10/2011 at $16: 37$

Please note that terms and conditions apply. 


\title{
From materials development to their test in IFMIF: an overview
}

\author{
N. Baluc, R. Schäublin, P. Spätig, N. Ilchuk, L. Veleva, \\ Z. Oksiuta ${ }^{a}$, J. Theile and M.Q. Tran
}

Ecole Polytechnique Fédérale de Lausanne (EPFL), Centre de Recherches en Physique des Plasmas, Association Euratom-Confédération Suisse, Switzerland

E-mail: nadine.baluc@psi.ch

Received 2 December 2010, accepted for publication 9 September 2011

Published 12 October 2011

Online at stacks.iop.org/NF/51/113006

\begin{abstract}
R\&D activities on fusion reactor materials in Switzerland focus on (1) the development of advanced metallic materials for structural applications in plasma-facing (first wall, divertor) and breeding blanket components of the future fusion power reactors, in particular oxide dispersion strengthened reduced activation ferritic steels and tungsten-base materials, (2) the modelling of radiation damage and radiation effects and (3) small specimen test technology for the future International Fusion Materials Irradiation Facility. The main objectives, examples of recent results and future activities are described in the case of these three $R \& D$ areas.
\end{abstract}

(Some figures in this article are in colour only in the electronic version)

\section{Introduction}

$R \& D$ activities on fusion reactor materials in Switzerland focus on (1) the development of advanced metallic materials for structural applications in plasma-facing (first wall, divertor) and breeding blanket components of the future fusion power reactors, in particular oxide dispersion strengthened (ODS) reduced activation ferritic (RAF) steels and tungsten-base materials, (2) the modelling of radiation damage and radiation effects and (3) small specimen test technology for the future International Fusion Materials Irradiation Facility (IFMIF). The scientific approach being used is based on investigating the structure/mechanics relationships at different length scales (nano-, micro-, meso- and macroscopic), before and after irradiation, using a wide range of experimental and numerical tools. For simulating experimentally the effects of $14 \mathrm{MeV}$ neutrons, irradiations are being performed with a mixed spectrum of high-energy protons and spallation neutrons in the Swiss Spallation Neutron Source (SINQ) located at the Paul Scherrer Institute (PSI), Switzerland, as well as with ions in the Joint Accelerators for Nano-science and Nuclear Simulation (JANNuS) located at Orsay/Saclay, France, and with fission neutrons in reactors in Belgium, Hungary and the Netherlands. The main objectives, examples of recent results and future activities are described just below in the case of the three R\&D areas mentioned just above.

a Present address: Department of Materials Science, Faculty of Mechanical Engineering, Bialystok Technical University, Wiejska 45C, 15-351 Bialystok, Poland.

\section{Status of R\&D activities in Switzerland}

\subsection{Development of advanced metallic materials}

The upper temperature for use of reduced activation ferritic/martensitic (RAFM) steels destined to structural applications in fusion power reactors is presently limited by a drop in mechanical strength at about $820 \mathrm{~K}$ [1]. ODS RAFM steels and ODS RAF steels appear promising structural materials for use up to about $920 \mathrm{~K}$ [1] and $1020 \mathrm{~K}$ [2], respectively. The upper temperature for use of ODS RAFM steels (which contain typically between 7 and $9 \mathrm{wt} \% \mathrm{Cr}$ ) can be increased only by about $100 \mathrm{~K}$ with respect to that of RAFM steels (7-9wt\% Cr), as it is actually restricted by the ferrite to austenite transformation ( $\gamma$-loop in the phase diagram). In contrast, the ODS RAF steels (which contain typically between 12 and $14 \mathrm{wt} \% \mathrm{Cr}$ ) do not go through an austenitization upon increasing the temperature, so that their upper temperature for use can be increased by about $200 \mathrm{~K}$ with respect to that of RAFM steels. Processing of ODS steels by hot isostatic pressing (HIPping) usually leads to materials with isotropic mechanical properties but relatively poor fracture properties [3], while processing by hot extrusion usually leads to materials with superior fracture properties [2] but non-isotropic mechanical properties.

Pure tungsten exhibits high strength at high temperatures, a good surface heat capability, a good resistance to erosion and does not suffer from high activation under neutron irradiation [4]. However, pure tungsten also shows low fracture toughness at all temperatures [5], associated with 


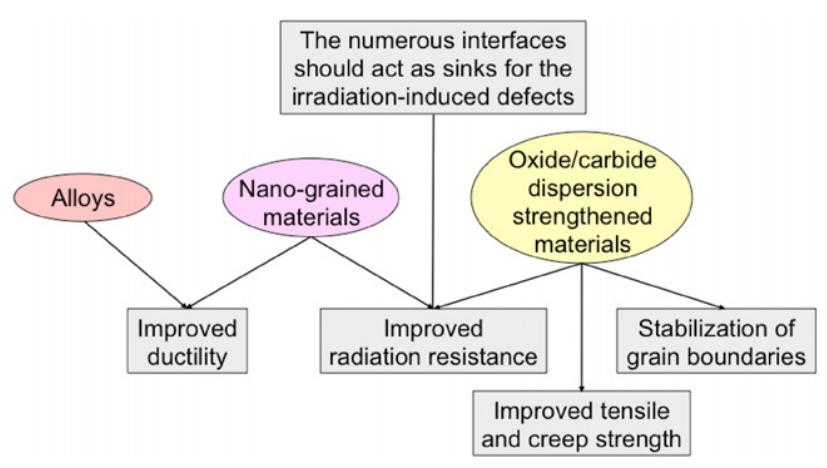

Figure 1. Development path of ODS RAF steels and reduced activation tungsten-base materials.

a high ductile-to-brittle transition temperature (DBTT), that are strongly dependent on the chemical composition and the production history, i.e. the microstructural state. The DBTT was found equal to about $1075 \pm 50 \mathrm{~K}$ and $1225 \pm 50 \mathrm{~K}$ for pure tungsten and $\mathrm{W}-1 \% \mathrm{La}_{2} \mathrm{O}_{3}$ (WL10) materials, for instance [6]. Therefore, it is usually considered that pure tungsten is well suited for plasma-facing applications, while the development of tungsten-base materials for high-temperature structural applications, such as for the thimble in finger-like units of the European helium-cooled divertor concept for DEMO-type reactors, is still at its very beginning.

In Switzerland present activities aim at developing ODS RAF steels and reduced activation tungsten-base materials with good tensile and creep strength and sufficient ductility, especially in terms of fracture toughness and DBTT, on the basis of the following ideas (figure 1): (1) alloys (e.g. W-V, $\mathrm{W}-\mathrm{Ti}, \mathrm{W}-\mathrm{Ta}$ compounds) and nano-grained materials are expected to show an improved ductility with respect to e.g. pure tungsten and normal grain-sized materials, respectively. (2) Nano-grained materials and materials reinforced with either oxide or carbide particles are expected to show improved tensile and creep strength and radiation resistance, as (i) the particles should act as obstacles for the propagation of mobile dislocations, (ii) the numerous grain boundaries and interfaces between the matrix and the particles should act as sinks for the irradiation-induced defects and (iii) the particles should also help stabilizing the numerous grain boundaries upon thermal annealing and/or irradiation.

2.1.1. ODS RAF steels. A variety of ODS RAF steels, namely $\mathrm{Fe}-(12-14) \mathrm{Cr}-2 \mathrm{~W}-(0.1-0.3-0.5) \mathrm{Ti}-0.3 \mathrm{Y}_{2} \mathrm{O}_{3}$ (in wt $\%$ ) have been successfully produced by mechanically alloying either elemental $\mathrm{Fe}, \mathrm{Cr}, \mathrm{W}$ and $\mathrm{Ti}$ powders or a pre-alloyed $\mathrm{Fe}-\mathrm{Cr}-\mathrm{W}-\mathrm{Ti}$ powder with $0.3 \mathrm{wt} \% \mathrm{Y}_{2} \mathrm{O}_{3}$ powder particles in a planetary ball mill, followed by compaction of the milled powders by HIPping. Detailed processing conditions are reported in e.g. [3]. It was found in particular that (1) hydrogen should be used as mechanical alloying atmosphere, in order to limit the oxygen content in the milled powders, (2) $14 \mathrm{Cr}$ materials exhibit a more stable ferritic microstructure than $12 \mathrm{Cr}$ materials and (3) $0.5 \mathrm{Ti}$ materials contain large $\mathrm{TiO}_{2}$ particles that can yield embrittlement effects. Therefore, recent R\&D activities focused on the $\mathrm{Fe}-14 \mathrm{Cr}-2 \mathrm{~W}-0.3 \mathrm{Ti}-$ $0.3 \mathrm{Y}_{2} \mathrm{O}_{3}$ ODS RAF steel. When prepared using elemental powders, this material was observed to contain a bimodal distribution of coarse grains, a few micrometres in size, and smaller grains, about $200 \mathrm{~nm}$ in size, as well as nano-sized particles enriched with Y, Ti and $\mathrm{O}$. The material exhibits high strength and reasonable elongation in tensile tests up to about 1020 K. However, it also shows relatively weak Charpy impact properties characterized by a DBTT of about $290 \mathrm{~K}$ and an upper shelf energy (USE) of about 3.2 J.

Fortunately, the Charpy impact behaviour of ODS RAF steels can be significantly improved by the use of thermomechanical treatments, such as hot pressing or hot rolling [3], and/or the use of $\mathrm{Fe}_{2} \mathrm{Y}$ particles, instead of $\mathrm{Y}_{2} \mathrm{O}_{3}$ particles, during the mechanical alloying process. Indeed, using $\mathrm{Fe}_{2} \mathrm{Y}$ powder particles instead of $\mathrm{Y}_{2} \mathrm{O}_{3}$ powder particles helps reducing the oxygen content in the mechanically alloyed powders of ODS RAF steels. However, recent transmission electron microscopy (TEM) observations of a $\mathrm{Fe}-14 \mathrm{Cr}-2 \mathrm{~W}-$ $0.3 \mathrm{Ti}-0.3 \mathrm{Y}_{2} \mathrm{O}_{3}$ material produced by mechanically alloying a $\mathrm{Fe}-\mathrm{Cr}-\mathrm{W}-\mathrm{Ti}$ pre-alloyed powder with $0.5 \mathrm{wt} \% \mathrm{Fe}_{2} \mathrm{Y}$ powder particles in hydrogen in a planetary ball mill and subsequent HIPping revealed that the nanoclusters that form during HIPping are larger and less densely distributed than those observed in the $\mathrm{Y}_{2} \mathrm{O}_{3}$ steel (figure 2, left and middle) [7]. Moreover, annealing of the $\mathrm{Fe}_{2} \mathrm{Y}$ steel at $1623 \mathrm{~K}$ for $1 \mathrm{~h}$ revealed significant grain growth and nanocluster coarsening. TEM investigations of the coarser nanoclusters in the annealed $\mathrm{Fe}_{2} \mathrm{Y}$ steel showed that they have an austenitic face centred cubic (fcc) structure. The $\mathrm{Fe}_{2} \mathrm{Y}$ material exhibits significantly better Charpy impact properties, with a DBTT of about $249 \mathrm{~K}$ and an USE of about $8.8 \mathrm{~J}$, than the $\mathrm{Y}_{2} \mathrm{O}_{3}$ material that exhibits a high DBTT of about $353 \mathrm{~K}$ and a very low USE of about $2.4 \mathrm{~J}$ (figure 2, right). In addition, the Charpy impact behaviour of the $\mathrm{Fe}_{2} \mathrm{Y}$ steel appears very close to the one of the material produced under the same conditions but without $\mathrm{Fe}_{2} \mathrm{Y}$ particles (figure 2, right). Thus, using $\mathrm{Fe}_{2} \mathrm{Y}$ intermetallic powder particles instead of $\mathrm{Y}_{2} \mathrm{O}_{3}$ oxide powder particles can be an effective approach for producing a softer material with improved impact fracture properties. However, stability of the nanoclusters in the $\mathrm{Fe}_{2} \mathrm{Y}$ steel upon aging and irradiation as well as high-temperature creep behaviour of the material are also important concerns and will have to be compared with those of the $\mathrm{Y}_{2} \mathrm{O}_{3}$ steel.

\subsubsection{Reduced activation tungsten-base materials. A} variety of tungsten-base materials, namely $\mathrm{W}-(0.3-1.0-2.0) \mathrm{Y}$, $\mathrm{W}-(0-3-1.0-2.0) \mathrm{Y}_{2} \mathrm{O}_{3}$ and $\mathrm{W}-(0.3-0.9-1.7) \mathrm{TiC}$ (in wt $\%$ ) have been successfully produced by mechanically alloying a pure W powder with either $\mathrm{Y}$ or $\mathrm{Y}_{2} \mathrm{O}_{3}$ or TiC powder particles in a planetary ball mill, in an argon atmosphere, followed by either cold pressing and sintering or HIPping. Detailed processing conditions are reported in e.g. [8]. The density and microhardness of the materials were found to increase with the $\mathrm{Y}, \mathrm{Y}_{2} \mathrm{O}_{3}$ or TiC content [8]. Following processing by sintering a maximum density of only about $88 \%$ was measured. Much higher density values in the range 95-97\% were achieved by compacting the various materials by HIPping instead of sintering.

Therefore, recent activities focused on the development of a W-2Y material by mechanically alloying elemental $\mathrm{W}$ and $\mathrm{Y}$ powder particles in argon in a planetary ball mill and subsequent HIPping [9]. A series of small ingots have been 

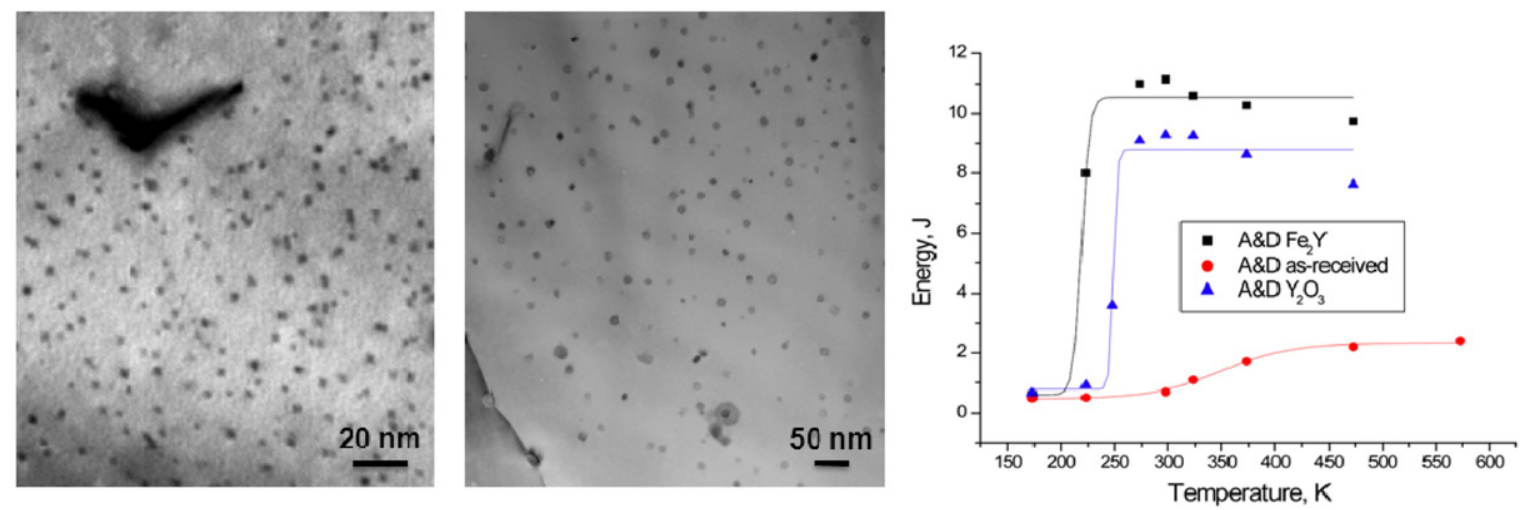

Figure 2. (Left) TEM image of nanoclusters in the $0.3 \mathrm{Y}_{2} \mathrm{O}_{3}$ material, (middle) TEM image of nanoclusters in the $0.5 \mathrm{Fe}_{2} \mathrm{Y}$ material and (right) Charpy impact behaviour of $\mathrm{Fe}-14 \mathrm{Cr}-2 \mathrm{~W}-0.3 \mathrm{Ti}-0.3 \mathrm{Y}_{2} \mathrm{O}_{3}$ ODS RAF steels manufactured by mechanically alloying a $\mathrm{Fe}-\mathrm{Cr}-\mathrm{W}-\mathrm{Ti}$ pre-alloyed powder from Aubert and Duval company (A\&D) with either $0.3 \mathrm{Y}_{2} \mathrm{O}_{3}$ particles or $0.5 \mathrm{Fe}_{2} \mathrm{Y}$ particles and HIPping.
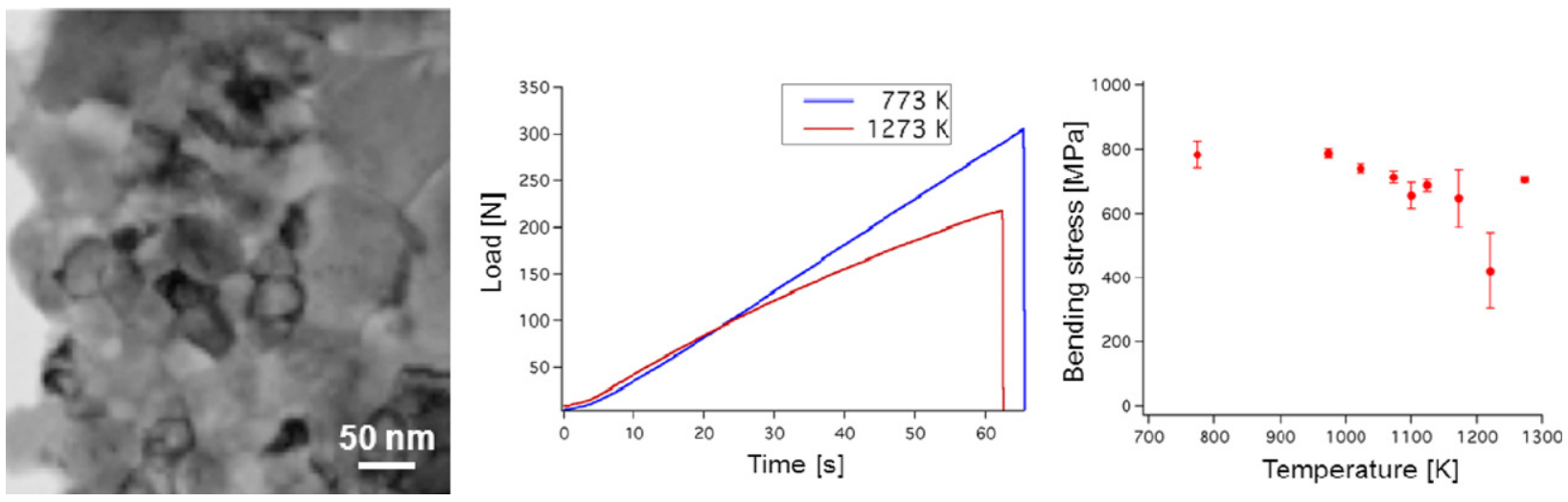

Figure 3. (Left) TEM image of the overall microstructure of a W-2Y material manufactured by mechanical alloying and HIPping, (middle) applied bending load versus time at two different test temperatures of 773 and $1273 \mathrm{~K}$, and (right) bending stress versus test temperature.

produced. Charpy impact specimens, tensile specimens and mini-bend bars were cut out from the ingots. The Charpy impact and tensile specimens were tested at high temperatures at Karlsruhe Institute of Technology (Germany) and the minibend bars were tested at the Centre of Research in Plasma Physics (Switzerland). TEM observations showed that the microstructure of the material is composed of a bimodal distribution of small grains with mean sizes around 50 and $150 \mathrm{~nm}$ (figure 3, left) and that yttrium transformed into yttria during the manufacturing process, yielding the formation of an inhomogeneous distribution of nano-sized particles, with sizes in the range $2-20 \mathrm{~nm}$, located inside the grains and at the grain boundaries. Charpy impact tests at $1273 \mathrm{~K}$ revealed that the material is brittle at that temperature. Non-standard three-point bend tests showed that the specimens failed in a brittle manner up to the highest investigated temperature of $1273 \mathrm{~K}$. Although some plastic deformation seems to have occurred at $1273 \mathrm{~K}$ (figure 3 , middle), fracture surface analyses showed that the material fractured in a purely brittle manner even at that high temperature. Therefore, the shape of that curve most probably reflects some unstable crack propagation. The bending stress was found to decrease with increasing the test temperature from about $800 \mathrm{MPa}$ at $773 \mathrm{~K}$ down to about $700 \mathrm{MPa}$ at $1273 \mathrm{~K}$, reflecting the decrease in elastic modulus with increasing temperature (figure 3 , right). Tensile tests at two different temperatures confirmed that the material is brittle at $1273 \mathrm{~K}$ but ductile at $1573 \mathrm{~K}$. Therefore, the DBTT should lie between about 1300 and $1500 \mathrm{~K}$. This indicates that, in spite of the small size of the grains, the material is very brittle up to very high temperatures. As the properties of tungsten-base materials are strongly dependent on the final production step(s), complex thermo-mechanical treatments are being developed in the aim to improve the fracture properties of these materials.

\subsection{Modelling of radiation damage and radiation effects}

In Europe a strong effort is put to conduct simulations of the underlying basic mechanisms at the origin of the degradation of the materials under irradiation in fusion conditions [10-12], because despite decades of experimental research there is still a lack of consistent understanding of those, such as the atomic displacement cascade that was never observed due to its lifespan in the picosecond range that is still out of reach experimentally. In Switzerland the main objective is to model and simulate the effects of irradiation-induced defects on (1) the microstructure and (2) the mechanical properties of pure iron and iron-base model alloys, as representative materials for RAFM steels (e.g. EUROFER 97), and of pure tungsten, as representative element for tungsten-base materials. The multiscale approach applied is based on various modelling methods, namely ab initio calculations, molecular dynamics (MD) based on the embedded atom method (EAM), and dislocation dynamics (DD) methods, allowing to span over 

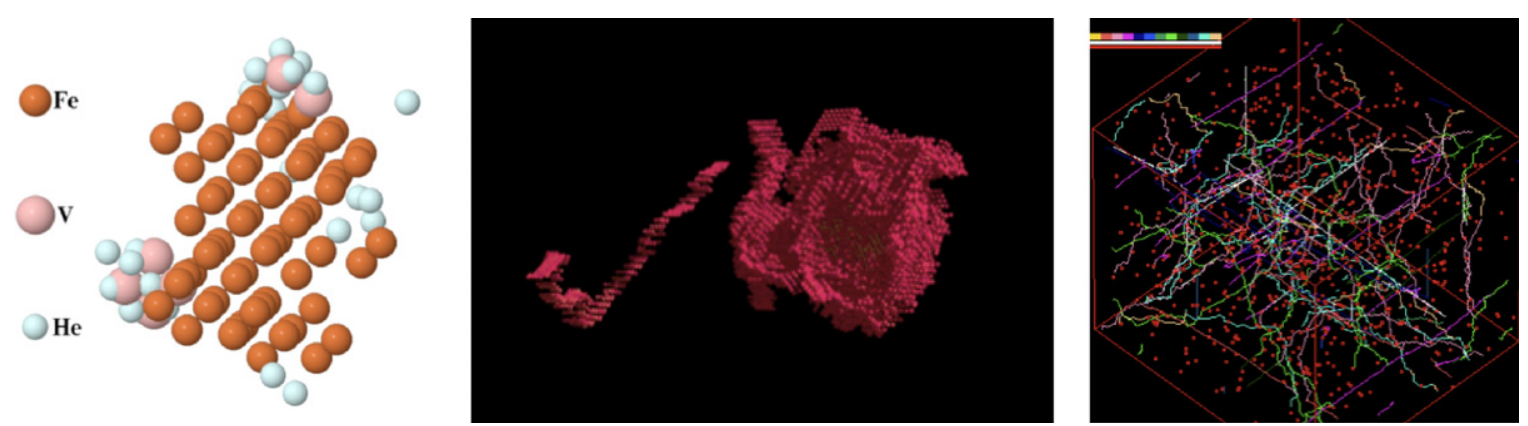

Figure 4. (Left) MD simulation of the structure of a large SIA cluster produced by a $20 \mathrm{keV}$ atomic displacement cascade at $300 \mathrm{~K}$ in iron containing 1.0 at $\%$ helium interstitial atoms ( $v=$ vacancy), (middle) MD simulation of the interaction of a mobile edge dislocation with a pressurized $4 \mathrm{~nm}$ helium bubble at $10 \mathrm{~K}$ in iron under imposed strain rate, promoting strong loop punching, and (right) DD simulation of the effect of $10^{22} \mathrm{~m}^{-3} 2 \mathrm{~nm}$ voids on $10^{12} \mathrm{~m}^{-2}$ mobile dislocations at $300 \mathrm{~K}$ in iron, yielding a strong radiation hardening in tensile tests.

scales. It is a multiscale inasmuch, as it is based on passing information or parameters and connecting key mechanisms, through space and time scales, from the electronic/atomic $(a b$ initio $)$ scale up to the structural element length and from femtoseconds up to more than seconds (DD method). Modelling results are at present being validated using the JANNuS facility by means of single, dual and triple ion beam irradiations/implantations of bulk specimens, as well as single and dual beam irradiations/implantations during in situ TEM observations [13,14]. In effect, JANNuS allows for an accurate selection of the impinging particle mass and energy, the irradiation dose and dose rate and the irradiation temperature, a prerequisite to the experimental validation of the effort of modelling at the atomic level.

Regarding the microstructural features of irradiated iron, starting at the lowest space scale, the self-interstitial atom (SIA) was scrutinized to identify the dependence of its formation energy, $E_{\mathrm{f}}^{\mathrm{SIA}}$, on temperature using $a b$ initio calculations [15] in view of providing data for the design of a better $\mathrm{Fe}-\mathrm{Fe}$ interatomic potential for MD simulations. Note that iron is the only body centred cubic (bcc) metal that accommodates a low energy $\left\langle\begin{array}{llll}1 & 1 & 0\end{array}\right)$ structure for the SIA, all others containing $\left\langle\begin{array}{llll}1 & 1 & 1\end{array}\right\rangle$ SIAs. An unusually strong dependence of $E_{\mathrm{f}}^{\text {SIA }}$ on the entropy was found, which actually allowed solving the dilemna raised in the 1980s on the structure of the SIA. The structure of a nanometric helium bubble in iron was critically investigated using MD simulations. It appears that helium has a tendency to spontaneous agglomeration with the generation of vacancies, leading to the formation of a helium bubble that is surprisingly stable, even at high pressures [16]. The resulting binding energies between helium atoms, vacancies and SIAs depend on the chosen empirical interatomic potentials, but with a good correspondence to $a b$ initio results [16]. At low and moderate pressures, the helium bubble adopts a shape close to a sphere with a radius obeying a classical equation of state that depends on the internal pressure and the free surface energy of iron [17]. At high pressures the bubble surface breaks and its shape depends then on the mechanical properties of iron, with an expansion of the bubble in the soft $\langle 110\rangle$ directions, giving rise to a polyhedron [17]. MD simulations showed that the presence of helium in iron has a strong influence on the damage produced by atomic displacement cascades [18, 19], in promoting the formation of large SIA clusters (figure 4, left).
The resulting damage, however, depends again strongly on the chosen empirical interatomic potentials [19], in particular on the $\mathrm{Fe}-\mathrm{He}$ interactions, and at present experimental validation of this choice is still lacking.

The microstructural features of irradiated tungsten were investigated using MD simulations and three different interatomic potentials [20-22]. With two of the most adequate potentials for defects [21,22] the lowest energy SIA in bcc tungsten appears to have a $\left\langle\begin{array}{llll}1 & 1 & 1\end{array}\right\rangle$ structure [23]. Nanometric loops formed by SIA platelets were investigated as a function of their size to find the lowest energy configuration. A strong dependence on the interatomic potential describing the $\mathrm{W}-\mathrm{W}$ interactions was found. For one of the potential [21] the lowest formation energy is achieved with the $1 / 2 a_{0}\left\langle\begin{array}{llll}1 & 1 & 1\end{array}\right\rangle\left\{\begin{array}{lll}1 & 1 & 1\end{array}\right\}$ loop, while in the case of another potential [22] the $1 / 2 a_{\mathrm{o}}\langle 111\rangle\left\{\begin{array}{lll}1 & 1 & 1\end{array}\right\}$ loop for radii smaller than $2 a_{\mathrm{o}}$ $(0.63 \mathrm{~nm}$, or about 20 SIAs $)$ and the $a_{\mathrm{o}}\langle 100\rangle\{100\}$ loop for larger sizes are favourable [23], which is in contradiction with experimental observations, though scarce. MD simulations of 10,20 and $50 \mathrm{keV}$ atomic displacement cascades at 10 and $523 \mathrm{~K}$ in pure tungsten were performed to assess the primary damage due to irradiation, with the dependence on the interatomic potential [24]. A new approach for connecting any general EAM potential to the universal potential was developed. The three investigated potentials were observed to produce similar results, even though their displacement thresholds are quite different [24]. A substantial difference in the spatial distribution of SIAs was, however, found. They are diffusing further away from the cascade core with two of them [20,21], relative to results obtained with the third one [22], which was attributed to the lower migration energy of SIAs obtained with the former two potentials. These potentials also predict a too high melting temperature and a too high formation energy for the $\langle 110\rangle$ SIAs. While the latter potential is more appropriate here, it yields a negative thermal expansion. No important impact of these effects on atomic displacement cascades was observed; probably even higher primary knockon atom (PKA) energies or higher temperatures are needed. This is similar to the case of iron, where largely different interatomic potentials describing the Fe-Fe interactions lead to similar cascade damage at low or moderate PKA energies [25].

Dislocation lines of the screw and edge types, dislocation loops, voids, helium bubbles and chromium precipitates in iron have been successfully modelled using MD simulations, in 


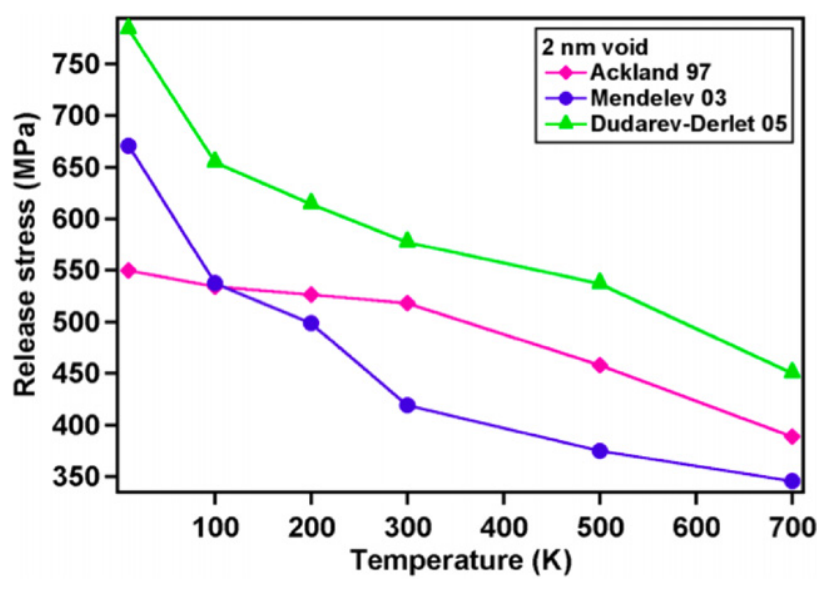

Figure 5. Release stress of an edge dislocation interacting with a $2 \mathrm{~nm}$ void in iron as a function of temperature using three different iron interatomic potentials.

view of simulating their impact on the propagation of mobile dislocations. It appears that these nano-sized defects act as strong obstacles to the propagation of mobile dislocations, the strongest being the voids, then the helium bubbles (figure 4, middle) [26-28], and the weakest the chromium precipitates [29]. When chromium is placed randomly in substitution in iron [30], it significantly hardens the matrix, following a classical behaviour of solid solution hardening. It should be noted that a strong dependence of the obstacle strength on the choice of the interatomic potential describing the $\mathrm{Fe}-$ Fe interactions was found [31], unlike their above-mentioned impact on cascade damage, despite recent efforts to match as closely as possible the elastic constants of iron, the formation energies of point defects and the magnetic behaviour of iron. Figure 5 shows that, for example, at the lowest investigated temperature the variation of obstacle strength amounts to about $40 \%$; it relates only to the choice of the iron interatomic potential [32-34].

The MD results were used for DD simulations, showing that the presence of a high density of nano-sized defects (figure 4, right) yields a strong radiation hardening [35], as measured experimentally in tensile tests. Concerning pure tungsten, the screw dislocation was investigated [36], in order to select the most appropriate potential to conduct simulations of the dislocation-defect interactions. Presently, the various tested potentials do not allow for a proper description of the screw dislocation core in pure tungsten [36].

In order to provide experimental validation, TEM appears the most suitable method as it provides direct imaging of the simulated defect structures. TEM image simulations were undertaken in order to close the gap between the modelling and experimental observations and to study the condition of visibility of the nanometric defects that are usually at the spatial resolution limit of the TEM [37].

\subsection{Small specimen test technology}

2.3.1. Small specimen test techniques. The main reason to develop and make use of small specimen test techniques is driven by the rather limited irradiation volumes in current and future irradiation facilities. Fracture toughness is particularly sensitive to the specimen size and geometry. Therefore, adequate methods to account for the specimen size and geometry effects on the fracture toughness have to be developed. Neutron irradiations are always detrimental for the fracture properties of RAFM and ODS RAFM steels, whose crystalline structure is bcc [38]. It is well known that the metals and alloys with a bcc structure exhibit a ductile-to-brittle transition of the fracture mode by decreasing the temperature. One major effect of neutron irradiation is to shift the transition region to higher temperatures, giving rise in particular to an increase in DBTT value in Charpy impact tests; this phenomenon is called embrittlement. The amplitude of the temperature shift depends on the irradiation conditions: temperature, neutron flux and fluence, amounts of helium and hydrogen produced by nuclear transmutation reactions, and so on. The method of the master curve, based on the determination of the reference temperature $T_{\mathrm{o}}$ that indexes a median universal toughness-temperature curve at $100 \mathrm{MPa} \mathrm{m}^{1 / 2}$, appears as a powerful method to determine the temperature shift with a limited number of specimens [38]. From very large databases on reactor pressure vessel (RPV) steels, it was established that the universal median toughnesstemperature curve reads as [39]

$$
K_{\text {med }}=30+70 \exp \left(0.019\left(T-T_{\mathrm{o}}\right)\right)
$$

and holds for toughness data obtained using 1T-thick compact tension $(\mathrm{C}(\mathrm{T}))$ specimens $(1 \mathrm{~T}=25.4 \mathrm{~mm})$. In addition, the master curve provides a statistical tool to describe the scatter of the toughness data at a given temperature through a three-parameters cumulative Weibull distribution function [40]. While having been initially developed for tempered bainitic RPV steels, the master-curve method was shown to describe the entire F82H-mod RAFM steel fracture database rather satisfactorily [41], provided that the specimen size effects are taken into account. Results of fracture toughness tests performed on F82H-mod specimens irradiated in the high flux reactor (HFR) at Petten (the Netherlands) under two irradiation conditions, namely at $333 \mathrm{~K}$ to $2.2 \mathrm{dpa}$ and at $573 \mathrm{~K}$ to $2.1 \mathrm{dpa}$, are reported in [42]. The data were obtained with sub-sized $\mathrm{C}(\mathrm{T})$ specimens and the toughness behaviour in the transition is shown in figure 6 (left), where both unirradiated and irradiated data are plotted to illustrate the temperature shift, $\Delta T_{\mathrm{o}}$, of the toughness-temperature curve. Since $\Delta T_{\mathrm{o}}$ stems from the concomitant radiation hardening, defined as the increase in yield stress after irradiation, $\Delta \sigma_{\mathrm{y}}$, a comparison of the temperature shifts for different irradiation conditions must take into account the corresponding radiation hardening values. A simple but reasonable approach is to consider a linear relation between $\Delta T_{\mathrm{o}}$ and $\Delta \sigma_{\mathrm{y}}$. Such an analysis was done for the F82H-mod RAFM steel by Yamamoto et al [43] who found: $\Delta T_{\mathrm{o}}=\alpha \Delta \sigma_{\mathrm{y}}$ with $\alpha=0.58$. While some refinements have already been proposed to better take into account the overall effects of irradiation on the plastic flow by calculating an average flow stress increase instead of $\Delta \sigma_{\mathrm{y}}$ [44], good predictions of embrittlement can be derived simply from the measure of the radiation hardening. It was also shown that the $\Delta T_{\mathrm{o}}$ shifts of the EUROFER 97 RAFM steel can be determined with ultra-small specimens [45]. Indeed, threepoints bend bars of $1 \times 1 \times 12 \mathrm{~mm}^{3}$ were tested before and after irradiation at $573 \mathrm{~K}$ to $0.5 \mathrm{dpa}$ in a $590 \mathrm{MeV}$ proton beam 

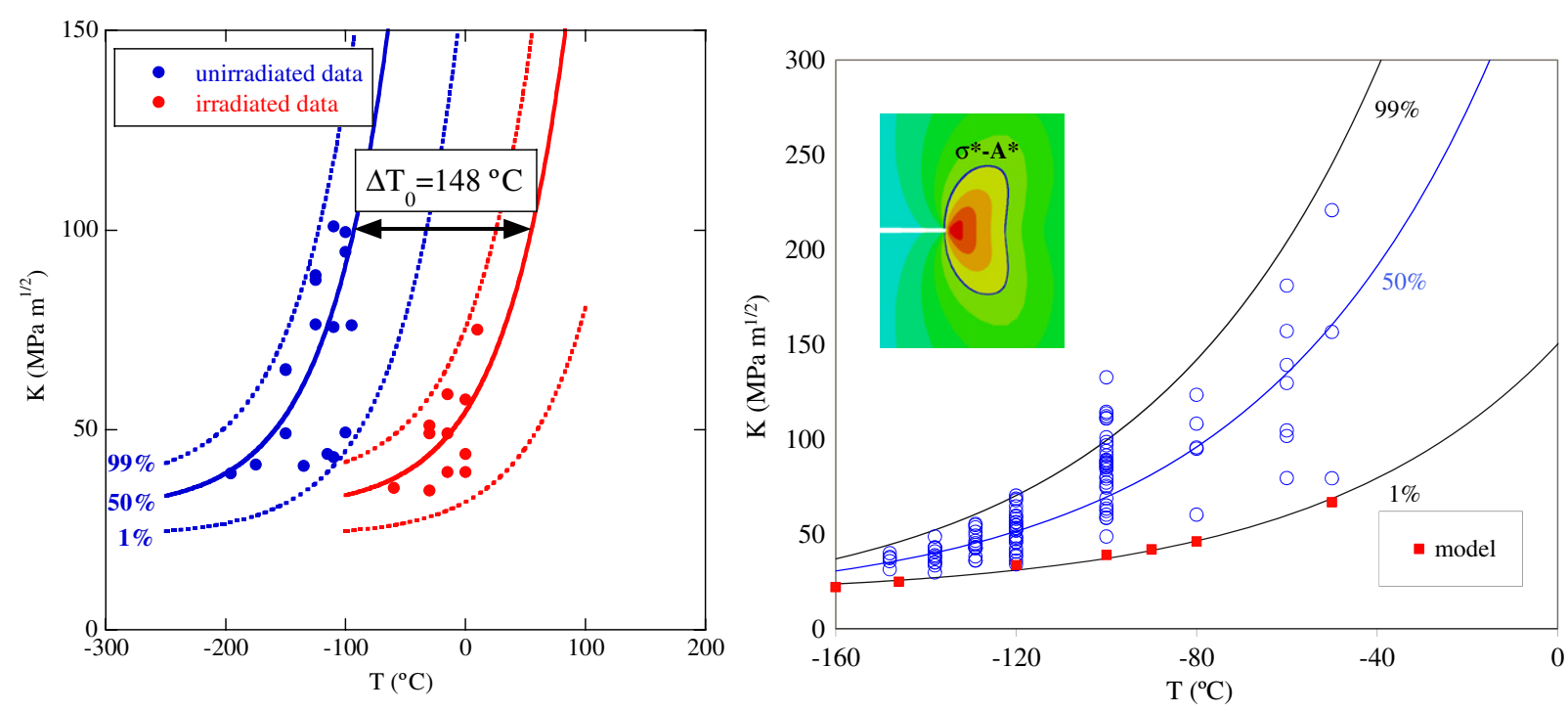

Figure 6. (Left) Shift of the toughness-temperature curve of the F82H-mod RAFM steel after neutron irradiation at $573 \mathrm{~K}$ to $2.1 \mathrm{dpa}$, measured with $0.18 \mathrm{~T} \mathrm{C}(\mathrm{T})$ specimens, and (right) description of the EUROFER 97 fracture toughness versus temperature with the master curve of equation (2) and model. The insert shows an iso-stress contour around a loaded crack: $\sigma^{*}-A^{*}$ is the local criterion for fracture of the model.

at the PSI (Switzerland). The $\Delta T_{\mathrm{o}} / \Delta \sigma_{\mathrm{y}}$ value obtained using these ultra-small specimens is 0.53 , which is quite consistent with the average value obtained for the F82H-mod RAFM steel (see above). Note that the $\Delta T_{\mathrm{o}}$ shifts were determined from the fits to the data below $100 \mathrm{MPa} \mathrm{m}^{1 / 2}$ to avoid the excessive constraint loss occurring in the upper transition region.

As mentioned above, the master-curve methodology was initially developed for RPV steels. Some authors raised questions and concerns regarding the applicability of the master curve to RAFM steels [46]. In particular, it was not clear whether the amplitude of the scatter of the toughness data in the transition region can be described by the RPV mastercurve approach properly. Indeed, in the case of the F82H-mod RAFM steel, the data assembled by Odette et al [41] revealed an excessive scatter with respect to the theoretical predictions of the master curve. In order to assess the applicability of the master curve to RAFM steels, a large number of fracture tests on the EUROFER 97 RAFM steel were undertaken [47]. The testing matrix included thick $\mathrm{C}(\mathrm{T})$ specimens, namely $0.87 \mathrm{~T}$ $\mathrm{C}(\mathrm{T})$, as well as sub-sized $0.18 \mathrm{~T}$ and $0.36 \mathrm{~T} \mathrm{C}(\mathrm{T})$ specimens. Enough data were obtained to fit not only $T_{\mathrm{o}}$ of equation (1) but also a second parameter to allow for an adjustment of the master-curve shape. In order to keep the meaning of $T_{\mathrm{o}}$ as the reference temperature at which the median toughness is $100 \mathrm{MPa} \mathrm{m}^{1 / 2}$, two parameters were fitted: $A$ and $T_{\mathrm{o}}$ of the equation $K_{\text {med }}=A+(100-A) \exp \left(0.019\left(T-T_{\mathrm{o}}\right)\right)$. The parameters were deduced from the method of the maximum likelihood and it was found that, for EUROFER 97, the data are very well described by a master curve of equation:

$$
K_{\text {med }}=12+88 \exp \left(0.019\left(T-T_{\mathrm{o}}\right)\right) .
$$

The toughness data versus temperature are plotted in figure 6 (right) along with the master curve, the $1 \%$ and $99 \%$ failure bonds, and the prediction of the model (see below). While being modest, the difference between equations (1) and (2) has all its importance when the testing is focused, or must be focused, in the lower transition region near the lower shelf. The major point to underscore here is that the specimen size effect on the measured fracture toughness, for a given size, decreases with the value of the toughness. In other words, it is highly desirable to test the small specimens in the lower part of the transition region. Thus, with the typical sub-sized facture specimens foreseen to be irradiated in IFMIF, it is of primary importance to have a good description of the master curve in the lower part of the transition and not to overlook the importance of the master-curve shape adjustments to determine $T_{\mathrm{o}}$ accurately. More details highlighting that point can be found in [47].

Finally, it is important to mention that modelling of the fracture behaviour is a necessary step to transfer the data from one specimen size to another. The red dots in figure 6 (right) refer to predictions based upon a local approach of fracture, where it is assumed that the onset of fracture is controlled by a critical stress/strain state at the crack tip. The simplest criterion of brittle fracture used to reconstruct the $1 \%$ failure bond in figure 6 (right) relies on the attainment of a critical maximum principal stress value $\left(\sigma^{*}\right)$ over a critical volume $\left(V^{*}\right)$ or area $\left(A^{*}\right)$ [38]. This criterion is illustrated in figure 6 (right) where an iso-stress contour around a crack tip is drawn. The procedure to calibrate the criterion $\sigma^{*}-A^{*}$ is described in detail in [48], and the practical application to transfer data from one specimen size to another is given in [49].

Research on specimen size effects on fracture toughness represents only a part of the efforts done in the development of small specimen test techniques for irradiated materials. Indeed, many different techniques using small specimens have been developed to assess the mechanical response of materials after irradiation. These tests include: tension, fatigue, Charpy impact, creep and stress corrosion cracking experiments as well as non-standard tests [50]. In the following, the discussion is restricted to the current development of one test technique for ultra-small specimens, which has the potential to extract the constitutive behaviour precisely. Let us emphasize that 

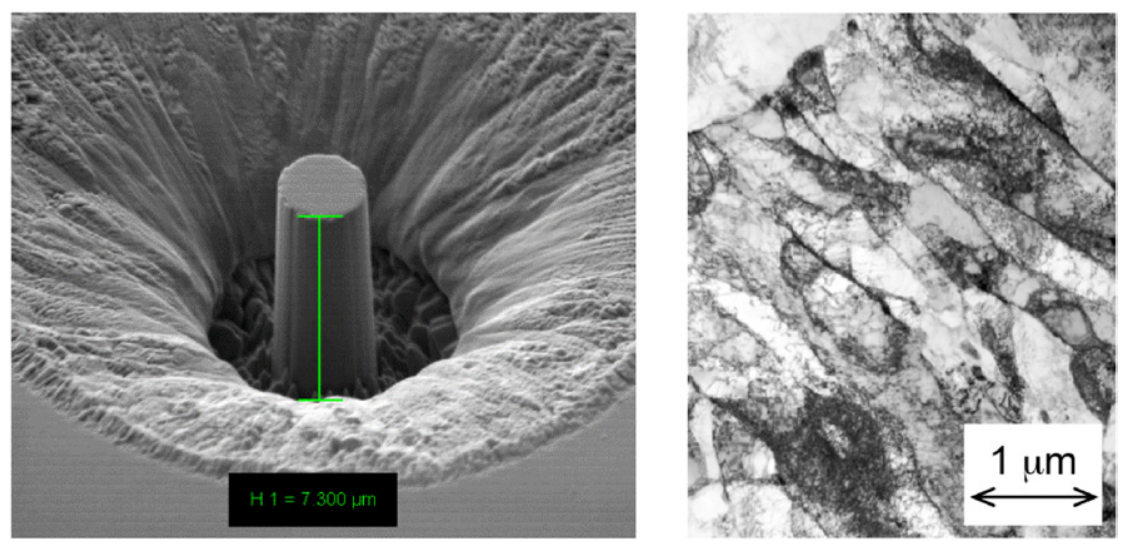

Figure 7. (Left) FIB fabricated micropillar of the EUROFER 97 RAFM steel, and (right) TEM image of the EUROFER 97 RAFM steel, highlighting the size of the small elongated tempered martensitic grains.

knowing the evolution of the constitutive behaviour with the irradiation parameters is essential to model that of the fracture properties, because the constitutive behaviour is intrinsically linked to the fracture behaviour. As highlighted in the preceding paragraph, the determination of the local critical stress/strain conditions for brittle fracture requires the use of finite element simulations, for which the constitutive behaviour is a fundamental input. This means that, in addition to the elastic constants characterizing the elastic response of the material, the yield stress as well as the strain hardening coefficients must be given. One of the major difficulties occurring with the tensile testing of RAFM steels after irradiation is related to the strong reduction in ductility which, for some irradiation conditions, can be such that the uniform elongation reduces to zero [51]. For those cases, it is therefore not possible to determine the strain hardening with tensile tests over a significant range of plastic strain. Hence, other deformation tests have to be considered. It has already been shown that compression tests are useful to determine the constitutive behaviour in the sense that the true stress-strain curve provided by compression tests is comparable to that obtained with tensile tests [52].

With the new opportunities offered by the focused ion beam (FIB) technique, it became possible to prepare cylindrical micropillars with a diameter and a height of several micrometres. The specimens used are typically $3-4 \mu \mathrm{m}$ in diameter and $7-8 \mu \mathrm{m}$ in height. There are several advantages to use such tiny specimens. For example, the true stress-strain relationship can be determined locally for any kind of irradiated specimen. Indeed, several micropillars can be machined from a tested fracture specimen and then deformed to determine the constitutive behaviour. Such a procedure also allows taking into account any irradiation dose gradient through an irradiation capsule by determining the correct radiation hardening of each specimen. Similarly, the constitutive behaviour could be obtained from small discs (similar to TEM specimens) irradiated with ion beams. Thus, in order to assess the possibility to determine the constitutive behaviour of RAFM steel with such micropillars, several specimens were machined by FIB and tested in compression using a $10 \mu \mathrm{m}$ diameter flat tip mounted in a G200 MTS nanoindenter. A picture of a micropillar is shown in figure 7 (left). Keeping in mind that the smallest microstructural units in RAFM steels are small elongated grains, whose shape derives from the lath microstructure of the quenched martensite and whose dimensions are smaller than $1 \mu \mathrm{m}$, one may expect that the size of such micropillars remains representative of the bulk. A TEM image of the EUROFER 97 RAFM steel is presented in figure 7 (right) where the small tempered martensitic grains are clearly visible.

A typical example of an experimental load-displacement curve obtained by deforming a micropillar is shown in figure 8 (left). Owing to the fact that the micropillars are tapered and that the bottom end is immovable, the conversion of the load-deformation curve into a true stress-strain curve is not straightforward. Nonetheless, in order to validate the micropillars as specimens able to represent the mechanical response of larger specimens, the experimental loaddisplacement values were compared with those calculated with finite element simulations. An axisymmetric model describing a tapered micropillar, as shown in figure 8 (right), was run with the ABAQUS software. We recall that the code simulates the multi-axial stress state based upon the von Mises stress potential and associated flow rule (J2-theory). This approach is based on continuum mechanics and consequently can be applied only to systems whose length scale is larger than any characteristic length scale of the microstructure. The calculated load-displacement curve is plotted along with the experimental one in figure 8 (left). The very good match between the two load-displacement curves indicates that the mechanical response of micropillars of the size used in this study is in good agreement with the predictions of continuum mechanics. Thus, the use of micropillars to assess the plastic flow properties of RAFM steels is appropriate. However, one emphasizes that the ultimate goal remains to convert the loaddisplacement curves into true stress-strain curves in the case of irradiated specimens, for which the true stress-strain curves are a priori unknown. Work is now in progress to set up a reliable inverse method of conversion to determine the true stress-strain curves, which will be based on the fitting of the calculated curves on the experimental ones. The procedure will mainly consist in fitting several parameters, namely the yield stress and strain-hardening coefficients.

2.3.2. Design of a creep-fatigue test module for IFMIF. There is a fundamental need to build an intense high-energy 

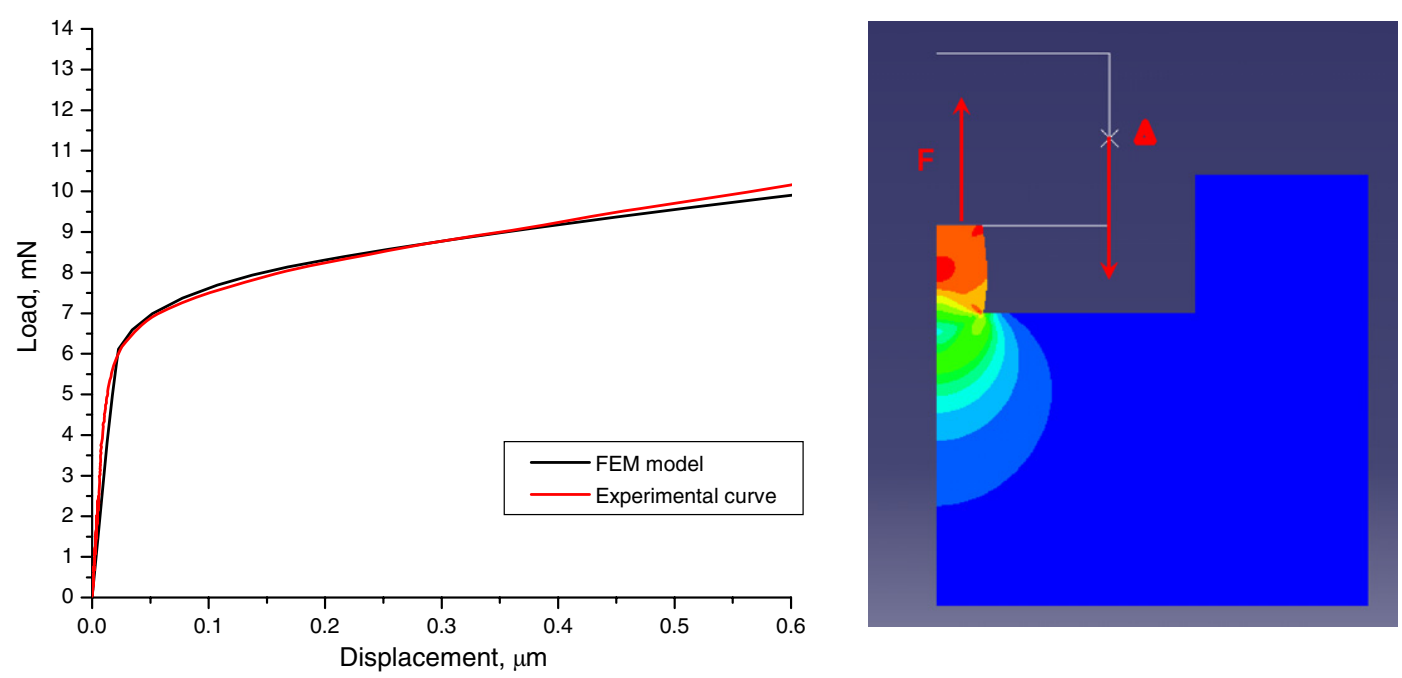

Figure 8. (Left) Comparison of an experimental deformation curve with a calculated one, and (right) axisymmetric finite element model showing the load $\mathrm{F}$, the displacement $\Delta$ of the flat indenter and the distribution of von Mises stresses.

neutron source to serve as a tool for (1) calibrating and validating the data generated using fission reactors and accelerator-based facilities (ion sources, spallation neutron sources) and (2) qualifying materials up to about full lifetime of anticipated use in a DEMO-type reactor. The primary mission of IFMIF is to generate a materials database to be used for the design and construction of various components and for the licensing and the assessment of the safe operation of DEMO-type reactors [53]. IFMIF will be an acceleratorbased, high-energy, intense neutron source that will be mainly composed of two $125 \mathrm{~mA}$ deuteron accelerators and a flowing liquid lithium target [54-56]. Under irradiation by a $10 \mathrm{MW}$ deuteron beam, the lithium target will produce a neutron flux of about $10^{17} \mathrm{n} \mathrm{s}^{-1}$ via $\mathrm{D}(\mathrm{Li}, x \mathrm{n})$ reactions. The specimens to be irradiated will be located just behind the lithium target, in a test cell composed of three modules [57, 58]: a high flux, a medium flux and a low flux test module. In the high flux test module the irradiation conditions will be very close to the ones expected to occur in a DEMO-type reactor at the level of the first wall, at least in terms of damage rate $(20-55 \mathrm{dpa} /$ year) and rates of production of helium (10-12 appm $\left.\mathrm{dpa}^{-1}\right)$ and hydrogen (40-50 appm dpa $\left.{ }^{-1}\right)$. In IFMIF, the majority of specimens made of structural materials will be irradiated in the high flux test module followed by post-irradiation examination in hot cells. In addition to static material irradiations in the high flux test module, more sophisticated in situ creep-fatigue tests on structural materials and in situ tritium release experiments on various tritium-breeding materials are foreseen in the medium flux test module, where a damage rate of 1-20 dpa/year will be reached [58].

In Switzerland, a test module for performing in situ creepfatigue tests in the medium flux test module of IFMIF, at temperatures in the range $570-820 \mathrm{~K}$, has been conceived and designed. This module is referred to as the creepfatigue test module (CFTM). The CFTM consists of three parallel testing machines, mounted on a frame, which will be operated independently. Each testing machine includes an actuator, a specimen with a gauge length of $8 \mathrm{~mm}$ and gauge

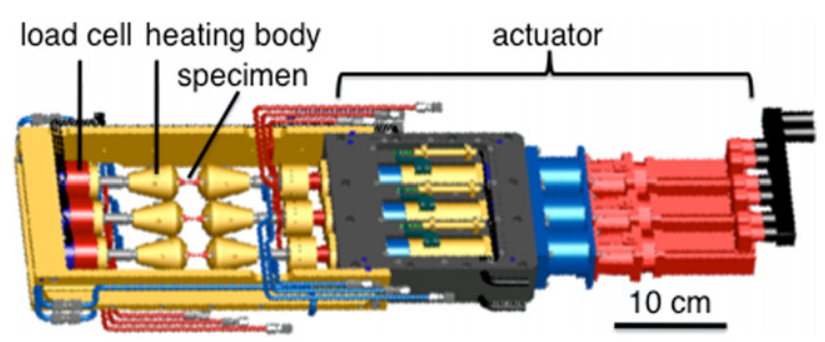

Figure 9. Schematics of the CFTM for IFMIF.

diameter of $4 \mathrm{~mm}$, a specimen holder, a load cell, a strain measurement system, a frame and a temperature controlling system (figure 9). The CFTM will be exposed to intense radiation fields, including both neutron and gamma fields, and will be thus made of temperature and radiation resistant elements. Part of the radiation heat will be used for heating the specimen. The rest of the heat, absorbed by the various parts of the CFTM, will be extracted by means of a helium gas (coolant) passing through independent cooling channels. The design has been validated by means of thermo-hydraulic calculations. Thermo-hydraulics' calculations showed that additional electrical heaters are not needed for reaching specimen temperatures up to about $820 \mathrm{~K}$. The targeted specimen temperatures can be reached and maintained by varying the helium flow rate and using tungsten blocks as heating bodies (figure 9). During testing he temperature gradient along the specimen gauge length will be less than $10 \mathrm{~K}$. The actuator will operate in the range of $\pm 12.5 \mathrm{kN}$ with unlimited hold times. For the time being, a single testing machine has been constructed and successfully tested at room temperature. It will be further validated by testing specimens of various materials, in particular the EUROFER 97 RAFM steel, at various higher temperatures up to about $820 \mathrm{~K}$. Additional calculations of neutron and gamma radiation effects will also be performed in order to get information on the eventual need of an additional shielding for the most radiation sensitive elements. 


\section{Summary}

To a large extent, the success of fusion energy depends on the existence of structural materials resisting the highly aggressive neutron environment provided by a deuterium-tritium fusion plasma. In order to develop such materials successfully, R\&D activities are being performed worldwide in various areas including processing and characterization experiments, modelling and validation of the basic mechanisms of production and accumulation of radiation damage and technological developments for the future irradiation facility IFMIF. The R\&D activities on fusion reactor materials performed in Switzerland are in line with these programmatic areas:

- First, new advanced metallic materials for structural applications are under development and small batches of ODS RAF steels and tungsten-base materials have been already produced. The microstructures and mechanical properties of these materials have been characterized before and after irradiation, and concerted efforts within the international community are being made to continuously improve them.

- Second, the role of modelling to gain insight into the multiscale nature of production and accumulation of irradiation-induced defects, followed by their interaction with mobile dislocations, has been outlined. For instance, MD simulations have been used to study the structure of helium bubbles in iron and irradiation-induced features in tungsten. Such simulations were also employed to calculate the release stress to unpin a dislocation from these small defects.

- Third, it has been highlighted that the development of small specimen test techniques is a critical issue for the development of qualified materials for a fusion power reactor. Indeed, only sub-sized specimens can be irradiated in IFMIF, from which the fusion reactor structure integrity will have to be assessed. Two examples of the use of sub-sized specimens for fracture and plastic flow property assessments were shown, for which the necessity to rely on modelling to account for the specimen size effects on the parameters to be determined was emphasized.

- Finally, in what concerns the technological development of IFMIF, a mock-up of the creep-fatigue test module has been designed and built. This module will be used for in situ experiments in IFMIF and is currently in the test phase.

\section{Acknowledgments}

The Paul Scherrer Institute is acknowledged for the overall use of its facilities. This work, supported by the European Communities under the contract of Association between EURATOM/Confédération Suisse, was carried out within the framework of the European Fusion Development Agreement. The views and opinions expressed herein do not necessarily reflect those of the European Commission. This work was also performed within the framework of the Integrated European Project 'ExtreMat' (contract NMP-CT-2004-500253) with financial support by the European Community. It only reflects the view of the authors and the European Community is not liable for any use of the information contained therein. Part of this work was supported by the Swiss Voluntary Contribution to the Broader Approach Agreement between Euratom and JAEA. The Swiss National Science Foundation is also acknowledged for its financial support.

(c) Euratom 2011.

\section{References}

[1] Lindau R. et al 2005 Present development status of EUROFER and ODS-EUROFER for application in blanket concepts Fusion Eng. Des. 75-79 989-96

[2] McClintock D.A., Sokolov M.A., Hoelzer D.T. and Nanstad R.K. 2009 Mechanical properties of irradiated ODS-EUROFER and nanocluster strengthened 14YWT J. Nucl. Mater. 392 353-9

[3] Oksiuta Z. and Baluc N. 2009 Optimization of the chemical composition and manufacturing route for ODS RAF steels for fusion reactor application Nucl. Fusion 49055003

[4] Baluc N. 2002 Assessment report on tungsten Final Report on the EFDA Task TW1-TTMA-002 Deliverable 5

[5] Zinkle S.J. and Ghoniem N.M. 2000 Operating temperature windows for fusion reactor structural materials Fusion Eng. Des. 51-52 55-71

[6] Rieth M. and Dafferne B. 2005 Limitations of W and $\mathrm{W}-1 \% \mathrm{La}_{2} \mathrm{O}_{3}$ for use as structural materials $\mathrm{J}$. Nucl. Mater. 342 20-5

[7] Oksiuta Z., Lewandowska M., Unifantowicz P., Baluc N. and Kurzydlowski K.J. 2010 Influence of $\mathrm{Y}_{2} \mathrm{O}_{3}$ and $\mathrm{Fe}_{2} \mathrm{Y}$ additions on the formation of nano-scale oxide particles and the mechanical properties of an ODS RAF steel Proc. 26th Symp. on Fusion Technology (Porto, Portugal, 27 September-1 October 2010); Fusion Eng. Des. at press (doi:10.1016/j.fusengdes.2011.01.023)

[8] Veleva L., Oksiuta Z., Vogt U. and Baluc N. 2009 Sintering and characterization of W-Y and W-Y2O3 materials Fusion Eng. Des. 84 1920-4

[9] Veleva L., Schäublin R., Plocinski T., Walter M. and Baluc N. 2010 Processing and characterization of a W-2Y material for fusion power reactors Proc. 26th Symp. on Fusion Technology (Porto, Portugal, 27 September-1 October 2010); Fusion Eng. Des. at press (doi:10.1016/j.fusengdes.2011.02.011)

[10] Möslang A. and Wiss T. 2006 Materials for energy-from fission towards fusion Nature Mater. 5 679-80

[11] Victoria M. et al 2007 Modelling irradiation effects in fusion materials Fusion Eng. Des. 82 2413-21

[12] Dudarev S.L. et al 2009 The EU programme for modelling radiation effects in fusion reactor materials: an overview of recent advances and future goals $J$. Nucl. Mater. 386 1-7

[13] Schaeublin R. 2007 Selection of experimental methods in JANNUS for 2007 Final Report on the EFDA Task TW6-TTMS-007-D12

[14] Serruys Y., Ruault M.O., Trocellier P., Henry S., Kaitasov O. and Trouslard P. 2005 Multiple ion beam irradiation and implantation: JANNUS project $\mathrm{Nucl}$. Instrum. Methods Phys. B 240 124-7

[15] Lucas G. and Schaublin R. 2009 Vibrational contributions to the stability of point defects in bcc iron: a first-principles study Nucl. Instrum. Methods Phys. Res. B 267 3009-12

[16] Lucas G. and Schaublin R. 2009 Stability of helium bubbles in alpha-iron: a molecular dynamics study J. Nucl. Mater. 386 360-2

[17] Hafez Haghighat S.M., Lucas G. and Schaublin R. 2009 State of a pressurized helium bubble in iron Europhys. Lett. 8560008

[18] Yu J.N., Yu G., Yao Z.W. and Schaublin R. 2007 Synergistic effects of PKA and helium on primary damage formation in Fe-0.1\%He J. Nucl. Mater. 367 462-7 
[19] Lucas G. and Schaublin R. 2008 Helium effects on displacement cascades in alpha-iron J. Phys.: Condens. Matter 20415206

[20] Finnis M.W. and Sinclair J.E. 1984 A simple empirical N-body potential for transition-metals Phil. Mag. A 50 45-55

[21] Ackland G.J. and Thetford R. 1987 An improved N-body semiempirical model for body-centered cubic transition-metals Phil. Mag. A 56 15-30

[22] Derlet P.M., Nguyen-Manh D. and Dudarev S.L. 2007 Multiscale modeling of crowdion and vacancy defects in body-centered-cubic transition metals Phys. Rev. B 76054107

[23] Fikar J. and Schaublin R. 2009 Atomistic simulations of nanometric dislocation loops in bcc tungsten Nucl. Instrum Methods Phys. Res. B 267 3218-22

[24] Fikar J. and Schaublin R. 2009 Molecular dynamics simulation of radiation damage in bcc tungsten $\mathrm{J}$. Nucl. Mater. 386 97-101

[25] Terentyev D., Lagerstedt C., Olsson P., Nordlund K., Wallenius J., Becquart C.S. and Malerba L. 2006 Effect of the interatomic potential on the features of displacement cascades in alpha-Fe: a molecular dynamics study $J$. Nucl. Mater. 351 65-77

[26] Schaublin R. and Chiu Y.L. 2007 Effect of helium on irradiation-induced hardening of iron: a simulation point of view J. Nucl. Mater. 362 152-60

[27] Hafez Haghighat S.M. and Schaublin R. 2007 Molecular dynamics modeling of cavity strengthening in irradiated iron Sci. Modeling Simul. 14 191-201

[28] Hafez Haghighat S.M. and Schaublin R. 2010 Influence of the stress field due to pressurized nanometric He bubbles on the mobility of an edge dislocation in iron Phil. Mag. 90 1075-100

[29] Terentyev D., Hafez Haghighat S.M. and Schaublin R. 2010 Strengthening due to $\mathrm{Cr}$-rich precipitates in $\mathrm{Fe}-\mathrm{Cr}$ alloys: effect of temperature and precipitate composition J. Appl. Phys. 107061806

[30] Hafez Haghighat S.M., Terentyev D. and Schäublin R. 2011 Atomistic simulation of the influence of $\mathrm{Cr}$ on the mobility of the edge dislocation in $\mathrm{Fe}(\mathrm{Cr})$ alloys $\mathrm{J}$. Nucl. Mater. at press (doi:10.1016/j.nucmat.2011.01.087)

[31] Hafez Haghighat S.M., Fikar J. and Schaublin R. 2008 Effect of interatomic potential on the behavior of dislocation-defect interaction simulation in alpha-Fe $J$. Nucl. Mater. 382 147-53

[32] Ackland G.J., Bacon D.J., Calder A.F. and Harry T. 1997 Computer simulation of point defect properties in dilute $\mathrm{Fe}-\mathrm{Cu}$ alloy using a many-body interatomic potential Phil. Mag. A 75 713-32

[33] Mendelev M.I., Han S., Srolovitz D.J., Ackland G.J., Sun D.Y. and Asta M. 2003 Development of new interatomic potentials appropriate for crystalline and liquid iron Phil. Mag. 83 3977-94

[34] Dudarev S.L. and Derlet P.M. 2005 A 'magnetic' interatomic potential for molecular dynamics J. Phys.: Condens. Matter 17 7097-118

[35] Hafez Haghighat S.M. 2010 Multiscale modelling of irradiation induced effects on the plasticity of $\mathrm{Fe}$ and $\mathrm{Fe}-\mathrm{Cr}$ EPFL PhD Thesis No 4667

[36] Fikar J., Schäublin R. and Björkas C. 2009 Atomistic simulation of $1 / 2\left\langle\begin{array}{lll}1 & 1 & 1\rangle\end{array}\right\rangle$ screw dislocations in BCC tungsten 1st Int. Conf. on New Materials for Extreme Environments (San Sebastian, Spain, 2-4 June 2008) vol 59 pp 247-52

[37] Schaublin R. 2006 Nanometric crystal defects in transmission electron microscopy Microsc. Res. Tech. 69 305-16

[38] Odette G.R., Yamamoto T., Rathbun H.J., He M.Y., Hribernik M.L. and Rensman J.W. 2003 Cleavage fracture and irradiation embrittlement: mechanisms, toughness measurements and implications to structural integrity assessment $J$. Nucl. Mater. 323 313-40

[39] Wallin K. 1993 Irradiation damage effects on the fracture toughness transition curve shape for reactor pressure vessel steels Int. J. Pressure Vessels Pip. 55 61-79

[40] Wallin K. 19931993 Macroscopic nature of brittle fracture $J$. Physique IV 3 575-84

[41] Odette G.R., Yamamoto T., Kishimoto H., Sokolov M., Spätig P., Yang W.J., Rensman J.W. and Lucas G.E. 2004 A master curve analysis of $\mathrm{F} 82 \mathrm{H}$ using statistical and constraint loss size adjustments of small specimen data $\mathrm{J}$. Nucl. Mater. 329-333 1243-7

[42] Spätig P., Bonadé R., Odette G.R., Rensman J.W., Campitelli E.N. and Mueller P. 2007 Plastic flow properties and fracture toughness characterization in the low transition of unirradiated and irradiated tempered martensitic steels $J$. Nucl. Mater. 367-370 527-38

[43] Yamamoto T., Odette G.R., Gragg D., Kurishita H., Matsui H., Yang W.J., Narui M. and Yamazaki M. 2007 Evaluation of fracture toughness master-curve shifts for JMTR irradiated F82H using small specimens J. Nucl. Mater. 367-370 593-8

[44] Odette G.R., He M.Y. and Yamamoto T. 2007 On the relation between irradiation induced changes in the master curve reference temperature shift and changes in strain hardened flow stress J. Nucl. Mater. 367-370 561-7

[45] Spätig P., Stoenescu R., Mueller P., Odette G.R. and Gragg D. 2009 Assessment of irradiation embrittlement of the Eurofer97 steel after $590 \mathrm{MeV}$ proton irradiation $\mathrm{J}$. $\mathrm{Nucl}$. Mater. 386-388 245-8

[46] Lucon E. 2007 A closer look at the fracture toughness of ferritic/martensitic steels J. Nucl. Mater. 367-370 575-80

[47] Mueller P., Spätig P., Bonadé R., Odette G.R. and Gragg D. 2009 Fracture toughness master-curve analysis of the tempered martensitic steel Eurofer97 J. Nucl. Mater. 386-388 323-7

[48] Bonadé R., Mueller P. and Spätig P. 2008 Fracture toughness behavior in the ductile-brittle transition region of the tempered martensitic Eurofer97 steel: experiments and modeling engineering Eng. Fract. Mech. 75 3985-4000

[49] Mueller P. and Spätig P. 2009 3D finite element and experimental study of the size requirements for measuring toughness on tempered martensitic steels $\mathrm{J}$. Nucl. Mater. $389374-84$

[50] Lucas G.E., Odette G.R., Sokolov M., Spätig P., Yamamoto T. and Jung P. 2002 Recent progress in small specimen test technology J. Nucl. Mater. 307-311 1600-8

[51] Odette G.R., He M.Y., Donahue E.G., Spätig P. and Yamamoto T. 2002 Modeling the multiscale of flow localization-ductility loss in irradiation damaged BCC alloys J. Nucl. Mater. 307-311 171-8

[52] Spätig P., Odette G.R., Lucas G.E. and Victoria M. 2002 On the mechanical properties of the advanced martensitic steel EUROFER97 J. Nucl. Mater. 307-311 536-9

[53] IFMIF International Team 2003 IFMIF Comprehensive Design Report

[54] Daum E., Ehrlich K., Jitsukawa S., Matsui H. and Möslang A. 2000 The international fusion materials irradiation facility IFMIF-an overview of user aspects Fusion Eng. Design 49-50 435-44

[55] Vladimirov P. and Möslang A. 2004 Comparison of material irradiation conditions for fusion, spallation, stripping and fission neutron sources J. Nucl. Mater. 329-333 233-7

[56] Moeslang A., Heinzel V., Matsui H. and Sugimoto M. 2006 The IFMIF test facilities design Fusion Eng. Des. 81 863-71

[57] Heinzel V. et al 2004 Overview on the IFMIF test cell development J. Nucl. Mater. 329-333 223-7

[58] Vladimirov P., Möslang A., Fischer U. and Simakov S. 2007 Material irradiation conditions for the IFMIF medium flux test module J. Nucl. Mater. 367-370 1574-9 